\title{
CHARACTERISATION, EXPRESSION AND ONTOGENY OF INTERLEUKIN- 6 AND ITS RECEPTORS IN ZEBRAFISH (Danio rerio)
}

\author{
Varela M., Dios S., Novoa B.*, Figueras A*. \\ Instituto de Investigaciones Marinas (IIM), CSIC. Eduardo Cabello 6, 36208 Vigo, \\ Spain. \\ *: Corresponding authors \\ Instituto de Investigaciones Marinas, CSIC. \\ Eduardo Cabello 6, 36208 Vigo, Spain. \\ Tel: 34986214463 \\ Fax: 34986292762 \\ E-mail: virus@iim.csic.es, antoniofigueras@iim.csic.es
}




\begin{abstract}
Interleukin-6 (IL-6) is one of the most pleiotropic cytokines due to its importance in both innate and adaptive immune responses and other physiological processes. In this study, we identified the zebrafish (Danio rerio) IL-6 homologue by investigating the synteny between the human (Homo sapiens), the fugu (Takifugu rubripes) and the zebrafish genome. Although zebrafish IL-6 showed a low sequence homology with other IL-6 sequences in other species, it presented a high structural similarity to human IL-6. We also analysed IL-6 expression in several different tissues, along with analysis of the expression of the genes that form the IL-6 receptor complex, IL-6R and gp130. After treatment with bacterial or viral stimuli, zebrafish IL-6 expression was modulated in a manner similar to that of other proinflammatory molecules, such as IL- $1 \beta$ and TNF$\alpha$. The expression of IL-6, IL-6R and gp130 was also studied during the ontogeny of zebrafish larvae using quantitative PCR and in situ hybridisation. Our results indicated that the transcripts were detected very early, increased during the first week of life and were predominantly expressed in the head, epidermis and neuromasts of the anterior and posterior lateral line system, suggesting their involvement in the normal development of these tissues.
\end{abstract}

\title{
1. Introduction
}

Interleukin-6 (IL-6) is one of the most pleiotropic and important cytokines due to its important role mediating the innate and adaptive immune responses (Akira et al., 1990, Naka et al., 2002). This molecule is produced by a wide variety of cell types, including macrophages, endothelial cells, glial cells, keratinocytes and fibroblasts, and participates in hematopoiesis, acute phase responses, metabolic processes and neurogenesis (Spooren et al., 2011).

In mammals, IL-6 initially binds to the membrane bound $\alpha$ receptor (IL-6R). Subsequently, the IL-6/IL-6R complex associates with the glycoprotein 130 (gp130), leading to gp130-homodimer formation and signal initiation, which includes activation of the JAK/STAT, ERK and PI3K signal transduction pathways (Scheller et al., 2011). In contrast to the ubiquitous expression of gp130, IL-6R exhibits a highly defined pattern of expression and is largely confined to hepatocytes and leukocytes, although 
the soluble form of this receptor allows other kinds of cells to respond to IL-6 (Jones et al., 2001; Heinrich et al., 2003).

Since its characterization in the eighties, under the name of B-cell differentiation factor (Hirano et al., 1985), IL-6 has been under continuous study due to its implication in important diseases. In fish, IL-6 was first described in Japanese pufferfish, by exploiting the synteny found between certain regions of the human and Takifugu rubripes versions of the gene (Bird et al., 2005), and afterwards in other fish species as part of EST analysis of immune gene-enriched cDNA libraries (Castellana et al., 2008; Iliev et al., 2007; Nam et al., 2007).

In spite of the importance of zebrafish (Danio rerio) as a model organism for fish and mammalian processes such as development, toxicological studies and diseases, the zebrafish IL-6 homologue has not been identified in any databases or in any genome projects thus far. For this reason, and in view of the importance of this cytokine in many biological processes, we sought to identify, characterise and describe the regulation of the expression and ontogeny of zebrafish IL-6. We additionally analysed the expression of the genes that form the IL-6 receptor complex.

\section{Material and methods}

\subsection{Sequence retrieval and analysis}

The zebrafish IL-6 sequence was initially investigated using the zebrafish genome (www.ensembl.org/Daniorerio/) assembly version Zv8 and Zv9, by exploiting the conservation of synteny between the human, the fugu and the zebrafish genomes.

Using the Gnomon prediction tool (http://www.ncbi.nlm.nih.gov/genome/guide/gnomon.shtml), the probable coding regions within the genomic DNA were identified and the amino acid sequences analysed using BLAST (Altschul et al, 1990) and FASTA (Pearson and Lipman, 1988). This analysis identified two contigs of the zebrafish genome assembly, version Zv8, (accession numbers: NW_00304079.1, NW_003043095.1) which seemed to code for a potential IL-6 homologue. The predicted cDNA sequence was further studied by designing primers for obtaining the full-length coding sequence of this gene. Both cDNA and exonic genomic sequences were subcloned into a PCR® 2.1 plasmid vector (Invitrogen) and transformed into One Shot TOP10F' competent cells (Invitrogen) following the manufacturer's instructions. Bacteria were cultured on 
LB/Ampicillin/IPTG/X-Gal plates for 24 hours at $37^{\circ} \mathrm{C}$, and the bacterial colonies were selected using the blue-white screening method. Positive colonies were selected and the insert was amplified using the M13 vector specific primers (M13F: GTAAAACGACGGCCAG, M13R: CAGGAAACAGCTATGA) for sequencing with an automated ABI 3730 DNA Analyser (Applied Biosystems). The resulting full-length Danio rerio IL-6 cDNA sequence was submitted to GenBank under accession number JN698962.

The predicted amino acid sequence was examined for the presence of a signal peptide using the SignalP program (http://www.cbs.dtu.dk/services/SignalP-2.0/) (Nielsen et al., 1997). Known protein domains were defined using Interpro (http://www.ebi.ac.uk/interpro/) and SMART (http://smart.embl-heidelberg.de/). The secondary structure of the protein was predicted using PSIPRED Server (Bryson et al., 2005) and PredictProtein (Rost et al., 2004).

An alignment with the human IL-6 was conducted using Modweb and ModBase (Pieper et al., 2011) and Pymol (The PyMOL Molecular Graphics System, Version 1.2r3pre, Schrödinger, LLC.). The protein structure modelling was conducted using 3DJIGSAW (http://bmm.cancerresearchuk.org/ 3djigsaw/) and I-TASSER (Zhang 2007; Roy et al., 2010) selecting the model with the best C-score. The TM-score was used as an indication of structure similarity.

A multiple sequence alignment with other vertebrate IL-6 sequences (Homo sapiens, NP_000591; Mus musculus, NP_112445; Gallus gallus, NP_989959; Takifugu rubripes, NP_001027894; Paralichtys olivaceus, ABJ53333; Sparus aurata, ABY76175; Oncorhynchus mykiss, NP_001118129) was generated using Clustal W from Bioedit using the Gonnet protein weight matrix. A phylogenetic tree was then constructed based on the amino acid distances of the aligned sequences and other IL- 6 family molecules by the neighbour-joining method (Saitou and Nei, 1987), bootstrapped 10,000 times, and represented using the MEGA 5 program (Tamura et al., 2011). The IL-6 family molecules used were the leukemia inhibitory factor (LIF) (Homo sapiens, AAA51699; Mus musculus, AAA37211), the ciliary neurotrophic factor (CNTF) (Homo sapiens, CAA43009; Mus musculus, NP_740756; Gallus gallus, NP_990823), the oncostatin M (ONCM) (Homo sapiens, AAH11589; Mus musculus, AAH99866) and the interleukin-11 (IL-11) (Homo sapiens, AAH12506; Mus musculus, AAI34355; Oncorhynchus mykiss, NP_001117854). 
The sequences of the IL-6 receptors, IL-6R and gp130, were obtained from the GenBank databases (NM_001114318 and NM_001113504).

\subsection{Animals}

Adults, embryos and larvae from wild type zebrafish were obtained from our experimental facility, where zebrafish are cultured following established protocols (Nusslein-Volhard et al, 2002; Westerfield, 2000) (also see http://zfin.org/zf_info/zfbook/zfbk.html).

\subsection{Experimental treatments}

Fish care and challenge experiments were conducted according the CSIC National Committee on Bioethics.

Naïve adult zebrafish were sacrificed using MS-222 (Tricaine methanesulfonate, Argent Chemical Laboratories, USA) overdose to analyse the basal expression of IL-6 and its receptor complex, IL-6R and gp130, in several organs. The kidney, liver, spleen and muscle from 12 fish were sampled and pooled, yielding a total of 3 biological replicates of 4 fish each per organ. Total RNA was isolated as described below.

Additionally, 36 adult zebrafish were intraperitoneally injected with $10 \mu \mathrm{L}$ of 1 $\mathrm{mg} / \mathrm{mL}$ LPS, and a second group of 36 fish was injected intraperitoneally with the same concentration of poly I:C in PBS solution, mimicking bacterial and viral infection, respectively. Thirty-six fish were injected with PBS and used as controls. Kidneys were sampled from anesthetized fish at 3, 6 and 24 hours post-stimulation (hps), and total RNA was isolated from 3 biological replicates of 4 fish per sampling point. The expression of IL-6, IL-6R and gp130 under stressed conditions was measured using real time PCR (qPCR) and compared with the basal expression of these genes. We also analysed the expression of TNF- $\alpha$ (NM_212859) and IL-1 $\beta$ (NM_212844) to compare the modulation of other proinflammatory molecules with the IL-6 expression profile.

An additional experiment was conducted to determine the expression of IL-6, IL-6R and gp130 during the early development of zebrafish larvae. Several spawnings from the same stock were induced to obtain larvae at different days post-fertilization (dpf), at 3-day intervals from $2 \mathrm{dpf}$ to $29 \mathrm{dpf}$. Different numbers of embryos or fish were used for each age group due to the differences in size to assure a minimum RNA amount, $1 \mu \mathrm{g}$, for cDNA transcription. Two biological replicates with 10-15 animals per 
group for individuals ranging from 2-14 dpf or 6-8 animals per group for individuals ranging from 17-29 dpf were used for RNA isolation.

\subsection{Nucleic acids isolation, $c D N A$ transcription and $P C R$ amplification}

Genomic DNA from zebrafish muscle was isolated using the Phenol-Chloroform method (Strauss et al., 2001). PCR amplification of genomic DNA was performed using $100 \mathrm{ng}$ of DNA with different combinations of specific primers depending on the desired fragment (Table 1).

Total RNA isolation was conducted both for adults and larvae using TRIzol reagent (Invitrogen), following the manufacturer's specifications, in combination with a RNeasy mini kit (Qiagen) for RNA purification after DNase I treatment. One microgram of total RNA was then used to obtain cDNA for qRT-PCR using the SuperScript III first-strand synthesis supermix (Invitrogen).

The expression patterns of IL-6 and the genes of the IL-6 receptor complex (IL6R and gp130), together with IL-1 $\beta$ and TNF- $\alpha$ for comparison purposes, were quantified using quantitative or real time PCR (qPCR) under both naïve conditions and after LPS or poly I:C stimulation. Specific PCR primers were designed from the selected sequences (Table 1) using the primer3 program (Rozen and Skaletsky, 2000), according to known qPCR restrictions. The efficiency of the primer pairs was then analysed with seven serial five-fold dilutions of cDNA and calculated from the slope of the regression line of the Cycle Thresholds (Cts) versus the relative concentration of cDNA (Pfaffl, 2001). A melting curve analysis was also performed to verify that no primer dimers were amplified. If these conditions were not accomplished, new primer pairs were designed. One $\mu \mathrm{l}$ of 5-fold diluted cDNA template was mixed with $0.5 \mu 1$ of each primer $(10 \mu \mathrm{M})$ and $12.5 \mu \mathrm{l}$ of SYBR Green PCR master mix (Applied Biosystems) in a final volume of $25 \mu \mathrm{l}$. The standard cycling conditions were $95^{\circ} \mathrm{C}$ for $10 \mathrm{~min}$, followed by 40 cycles of $95^{\circ} \mathrm{C}$ for $15 \mathrm{~s}$ and $60^{\circ} \mathrm{C}$ for $1 \mathrm{~min}$. All reactions were carried out as technical triplicates. The relative expression levels of the genes were normalized using 18S ribosomal RNA (BX296557) expression as a housekeeping gene control, which was constitutively expressed and not affected by the treatments, following the Pfaffl method (Pfaffl, 2001). Fold change units were calculated by dividing the normalised expression values of stimulated tissues by the normalised expression values of the controls. For basal conditions, the expression units were calculated by dividing the normalised expression values of each organ by the 
normalised expression value of the liver. In the case of ontogeny, expression units were calculated by dividing the normalised expression values of each sample point by the normalised expression value at $2 \mathrm{dpf}$. For the biological replicates, the average relative level of expression from each replicate was considered as a single point and the mean and standard error calculated.

\subsection{Whole-mount in situ hybridisation (ISH)}

Sense and antisense RNA-probes were designed to create fragments that were between 713 and 720 bases long. They were produced with the PCR amplification method under standard PCR conditions ( 35 cycles, $60{ }^{\circ} \mathrm{C}$ annealing temperature) using specific primers (Table 1). The sense probe had incorporated the promoter sequence necessary for labelling purposes (SP6 promoter, ACGATTTAGGTGACACTATAGAA), while the antisense probe had incorporated the T7 promoter (AGTTAATACGACTCACTATAGGGATT). RNA-probes were prepared using DIG-RNA Labelling Kit (SP6/T7) (Roche) according to the manufacturer's instructions.

The whole-mount in situ hybridisation (ISH) was performed on 3 dpf zebrafish embryos essentially as reported by Thisse and Thisse (2008). Embryos were fixed overnight in 4\% paraformaldehyde (PFA, Sigma) in phosphate-buffered saline (PBS). Embryo pigmentation was suppressed by $3 \%$ hydrogen peroxide treatment during 30 minutes. Next, the embryos were washed in PBT (PBS plus 0.1\% Tween 20, Sigma), treated with methanol and stored at $-20^{\circ} \mathrm{C}$. Methanol-stored embryos were re-hydrated in a methanol/PBS series, permeabilized using proteinase $\mathrm{K}(10 \mu \mathrm{g} / \mathrm{ml})$ (Roche), prehybridized, and then hybridized overnight at $70{ }^{\circ} \mathrm{C}$ with $100 \mathrm{ng}$ of the corresponding probe in $200 \mu \mathrm{l}$ of hybridisation mix (HM: 50\% formamide, 5x SSC, 0.1\% Tween 20, $50 \mathrm{mg} / \mathrm{ml}$ heparin and $0.5 \mathrm{mg} / \mathrm{ml} \mathrm{tRNA}$ ). After HM/SSC and SSC/PBT washing series, embryos were pre-incubated in blocking solution ( $2 \%$ sheep serum and $2 \mathrm{mg} / \mathrm{ml} \mathrm{BSA}$ in PBT) and then incubated overnight at $4{ }^{\circ} \mathrm{C}$ with pre-absorbed alkaline phosphataseconjugated anti-DIG antibodies (Roche) diluted 1:2000 in blocking solution. After PBT washing, embryos were pre-soaked in staining buffer and then incubated in NBT/BCIP (nitro blue tetrazolium/5-bromo-4-chloro-3-indolyl-phosphate) (Roche) for blue staining. Stained embryos were cleared in $100 \%$ glycerol, observed under an AZ100 microscope (Nikon) and photographed with a DS-Fi1 digital camera (Nikon). 


\subsection{Statistical analysis}

Results are presented as mean \pm standard error of mean (SEM). The data were analysed using one-way analysis of variance and Tukey's test, and differences were considered significant at $\mathrm{p}<0.05$.

\section{Results}

\subsection{IL-6 gene organization and bioinformatics analysis}

A high degree of synteny was found between the human chromosome 7 , the fugu scaffold 449 and zebrafish chromosome 19. In both cases, the genes SP4, CDCA7L, TOMM7 and HYCCIN were found in the region of IL-6 gene, but they appeared in a different order. The genes SP4 and HYCCIN were in the same contig of the Zv9 assembly version of the zebrafish genome (CU928128.15) with the same orientation, involving a chromosomal inversion that affected the zebrafish HYCCIN, TOMM7 and IL-6 genes (Fig. 1a).

The gene organization of $D$. rerio IL-6 was obtained using the predicted zebrafish IL-6 ORF sequence and two contigs of the Zv8 assembly version of the zebrafish genome (accession numbers: NW_00304079.1, NW_003043095.1) that were again amplified and sequenced. The genomic organization of zebrafish IL-6 was the same as that observed in the human IL-6 gene and other fish IL-6 known sequences (Fig. 1b) and was found to have five exons and four introns. The intron splicing consensus (GT/CAG) was conserved at the $5^{\prime}$ and $3^{\prime}$ ends of the introns.

The ORF of the zebrafish IL-6 was obtained and confirmed using PCR and specific primers (Table 1) that amplified the full-length IL-6 cDNA (Fig. 2). The transcript consisted of a 696 bp sequence that coded for a predicted 231 amino acid protein. Zebrafish IL-6 had a predicted signal peptide, an IL-6 domain and a four-helical cytokine core. Four possible glycosylation sites were also predicted at amino acids 86, 110, 138 and 195.

A multiple alignment with other known IL-6 amino acid sequences showed conservation zones among the species (Fig. 3a). The consensus IL-6 family signature (C-X(9)-C-X(6)-GL-X(2)-Y-X(3)-L) showed some changes in the zebrafish IL-6 protein, in which the Glycine is replaced by Valine and last Leucine by Tryptophan. Zebrafish IL-6, like the other fish IL-6, only has two conserved cysteine residues out of the four that are involved in disulfide bond formation. The values of similarity and 
identity with other IL-6 sequences were low, as it happens in other fish species (Table 2). Phylogenetic analysis further demonstrated that the zebrafish IL-6 was more closely related to other fish IL-6 with a bootstrap value of 58\%, although it seems to constitute a different clade than the one formed by fugu, gilthead seabream, flounder and trout (Fig. 3b). The tertiary structure of zebrafish IL-6 was modelled with a high confidence (C-score: -0.76), and a TM-score of 0.62 indicated a model of correct topology and an important similarity between the zebrafish and human structures (Fig. 4).

\subsection{Tissue-related expression}

In adult zebrafish, IL-6 was predominantly expressed in the kidney and spleen. The IL-6 receptor complex genes IL-6R and gp130 were detected in all analysed tissues. IL-6R expression was notably higher in the kidney than in the spleen and muscle, where the expression was lower than in any other tissue. The expression level of gp130 was remarkably similar within all studied tissues and, although it appeared that higher levels of expression occurred in the kidney and spleen, no significant differences were observed (Fig. 5).

\subsection{Inflammatory challenge}

The proinflammatory cytokines analysed in this study followed a very similar expression pattern to that of IL-6. Kidney expression of IL-6, TNF- $\alpha$ and IL-1 $\beta$ increased significantly following exposure to LPS or poly I:C (Fig. 6). A decrease in the expression of these genes was observed after $3 \mathrm{hps}$ with the exception of IL-6, for which the expression was maintained until 6 hours after injection. At 24 hps, the expression levels of the pro-inflammatory cytokines returned to the baseline level.

In contrast, the expression of the IL-6 receptor complex genes IL-6R and gp130 was not significantly regulated at any time after LPS or poly I:C stimulation.

\subsection{Ontogeny \& ISH}

We also analysed the expression level of IL-6, IL-6R and gp130 during zebrafish early development (Fig. 7). Transcripts of these genes were detected at all sampling points between 2 to $29 \mathrm{dpf}$. In all cases, we observed that expression gradually increased during the first week post-fertilization. Expression then appeared to reach a steady state with the exception of IL-6R, for which two peaks were observed at 17 and 
23 dpf. In the case of IL-6, the results also suggested a decrease at the end of the larvae's first month of life.

For whole mount in situ hybridisation, the expression pattern at 3dpf appeared similar for both IL-6 and its receptor complex genes. Our results showed that these three molecules were predominantly expressed in the head, epidermis and neuromasts of the anterior and posterior lateral line system. Moreover, strong expression was observed in the cells surrounding the mouth opening, in the olfactory placodes and in the lateral fins (Fig. 8).

\section{Discussion}

In the present work, we identified the zebrafish IL- 6 by exploiting the synteny between the human, the fugu and the zebrafish genome. We used several genes situated on human chromosome 7 and fugu scaffold 449, close to the IL-6 gene, to find the $D$. rerio IL-6 homologue. This gene was identified on the zebrafish chromosome 19, but in a different position with regards to its order within the block of surrounding genes compared to the human chromosome. A chromosomal inversion that affects the IL-6, TOMM7 and HYCCIN genes was observed. This is not an isolated event, as many studies show that blocks of conserved syntenies between zebrafish and humans are large, but the gene order is frequently inverted and transposed (Postlethwait et al., 2000; Liu et al., 2002). The zebrafish IL-6 was predicted to contain 231 amino acids with a 23-amino acid signal peptide. It was also predicted that this molecule possesses a fourhelical cytokine core with a conserved IL-6/G-CSF/MGF family signature (C-X(9)-C$\mathrm{X}(6)-\mathrm{G}-\mathrm{L}-\mathrm{X}(2)-\mathrm{Y}-\mathrm{X}(3)-\mathrm{L})$, with the exception of the Glycine and the final Leucine residue. In the zebrafish IL-6, the Glycine (GGC) was substituted for Valine (GTC) and Leucine (TTG) for Tryptophan (TGG).

Of all the described IL-6 sequences in fish, fugu is the only one for which this characteristic family motif remains unchanged. All other known fish IL-6 sequences show some minor modifications. In the case of trout IL-6, the first cysteine of the family signature is displaced and there are only 7 amino acids between the first and the second cysteine. In most of the cases, including zebrafish IL-6, there are amino acid substitutions. For IL-6, only the $3^{\text {rd }}$ and $4^{\text {th }} \mathrm{C}$ residues of the 4 important $\mathrm{C}$ residues in mammals are conserved in all known IL-6 teleosts orthologs, with the exception of 
seabream IL-6, in which only $1 \mathrm{C}$ residue is conserved (Bird et al., 2005; Castellana et al., 2008; Iliev et al., 2007; Nam et al., 2007). Phylogenetically, zebrafish IL-6 was grouped with other fish IL-6 and, as occurs with other cytokines, the identity and similarity of the zebrafish IL-6 are relatively low compared to their counterparts in other species. The low identity between the zebrafish IL-6 and IL-6 from higher vertebrates is not an isolated event, as this also happens with other cytokines such as IL-1 $\beta$ and IL-18 (Huising et al., 2004). In spite of this, there was a high conservation of the threedimensional structure of zebrafish IL-6, which suggests a functional conservation among species.

Tissue-related expression of zebrafish IL-6 gene was examined by qPCR in the kidney, spleen, muscle and liver of non-stimulated adult zebrafish. Transcripts of this gene were detected in all analysed tissues. We observed the highest expression in kidney and spleen, in which expression was 5 and 4 times higher, respectively, than in the liver. The lowest expression level was detected in muscle and liver. The results obtained in fugu described the expression of IL-6 only in the kidney but not in any other tissue (Bird et al., 2005). Also, Iliev et al. (2007) detected the highest expression in the ovary of trout while Castellana et al. (2008) reported the highest values in the muscle and skin of gilt head seabream. These authors also detected IL-6 transcripts in other tissues such as spleen, but in smaller amounts. In flounder, basal expression was not detected in the analysed tissues (Nam et al., 2007). The results reported so far display variable data regarding the basal expression of this gene in fish tissues, probably because the technique used in all cases was RT-PCR, which is less sensitive than the qPCR used in this study. Liongue et al. (2007) identified the zebrafish IL-6R and gp130 ortologues. They focused on the phylogenetic analysis of these molecules, therefore their pattern of expression remained unknown until this study. IL-6R transcripts were detected in all analysed tissues, but the highest expression level was found in kidney and liver. To our knowledge, this is the first analysis of tissue-related IL-6R expression in fish and our results agree with the data obtained in mammals, in which IL-6R is mainly produced by leukocytes and hepatocytes (Chalaris et al., 2011; Rose-John et al., 2006), which are especially abundant in kidney and liver, respectively. With regard to the other component of the receptor complex, little is known about gp130 expression in fish. Santos et al. (2007) described a ubiquitously expressed gp130-like molecule in Japanese flounder. In higher vertebrates, this molecule is also ubiquitously expressed (Hibi et al., 1990). Gp130 was widely studied during the nineties, due to its relationship 
with different cytokines such as IL-6, LIF, CNTF and IL-11 (Hibi et al., 1990; Ip et al., 1992; Nandurkar et al., 1996). Gp130 is the common signal transducer for all of these IL-6-family cytokines, which could explain its presence in all cell types.

IL-6 is one of the most important proinflammatory cytokines that, together with TNF- $\alpha$ and IL- $\beta$, constitutes the first cytokines released after host exposure to pathogens. We compared the expression level of these three genes at different times after intraperitoneal stimulation with LPS and poly I:C. The transcription level increased significantly for all of these cytokines during the first hours after the pathogen-associated molecules (PAMPs) exposure. In mammals, as in another fish species, it is known that IL-6 expression can be induced by LPS or poly I:C, as well as by cytokines such TNF- $\alpha$ and IL-1 $\beta$. This would explain why IL-6 transcript expression was maintained for up to 6 hours after injection. These results also suggest that the maximum expression for IL-6 took place between 3 and 6 hps for both LPS and poly $\mathrm{I}: \mathrm{C}$, probably in response to prior induction of TNF- $\alpha$ and IL-1 $\beta$. This was also the case for Vibrio anguillarum infected seabream, where an increase in the IL-6 expression in head kidney was observed at 4 hours post-stimulation (Castellana et al, 2008). A trend of increased expression for the receptor complex could be observed, with a modest transcript increase at $6 \mathrm{hps}$. This could indicate a peak of expression before or after this sampling point. This would be consistent with the regulation of these complexes demonstrated in several studies in mammals (Schooltinck et al., 1992; Snyers and Content, 1992; Vallières and Rivest, 1997), where it has been shown that both IL-6R and gp130 are regulated by TNF- $\alpha$, IL-1 $\beta$, IL-6 and LPS in different ways depending on the cell type.

IL-6 and its receptors are also involved in processes such as hematopoiesis and the growth, differentiation and activation of certain cell types. The expression of IL-6 in the ovary of some organisms and some embryonic cellular lines also points to its involvement in reproduction and development (Chung et al., 2000; Iliev et al., 2007). Expression analysis of IL-6, IL-6R and gp130 during ontogeny of zebrafish larvae showed that the transcripts were present at all sampled points. Detection took place immediately after the larvae hatched (2-3dpf) and peaked during the first week of life of the individuals. This suggests that the organism needs these molecules and their biological activities for proper development or early survival. In support of this, gp130deficient mice are embryonically lethal and conditional deletions of this gene result in 
hematopoietic, immunological, neurological and hepatic defects (Yoshida et al., 1996, Betz et al., 1998). IL-6 or IL-6R \% mice are viable, but they suffer important alterations related to inflammation, organ regeneration and metabolism (Schirmacher et al., 1998; Wallenius et al., 2002).

IL-6 also plays a critical role in the nervous system. This system can produce some cytokines, such as IL-1 $\beta$, IL-6 and TNF- $\alpha$, and their receptors during both inflammatory responses and normal development. Receptors for a variety of cytokines, including the IL-6, have been localized in several brain areas (Mehler and Kessler, 1997; Szelényi, 2001). Under non-pathological conditions, some cytokines of the IL-6 family may participate in the development and the function of the central nervous system (Taga and Fukuda, 2005). This would include gp130, as it is the common signal transducer for several members of this cytokine family. The results of the $3 \mathrm{dpf}$ larvae in situ hybridisation suggest that these genes could be involved in the neurogenesis and development of zebrafish. ISH clearly revealed the appearance of IL-6, IL-6R and gp130 transcripts in neuromasts. These mechanoreceptor organs of the lateral line system are distributed in the head and along the fish trunk. They are composed of several cell types, among which are mechanosensory hair cells and multipotent progenitors. Although several authors have demonstrated the existence of macrophages around the neuromasts, hybridisation seemed to occur in cells within the neuromasts and the staining appeared specifically in a group of cells at the centre of the cell cluster, including the location where the hair cells will eventually arise. Gallardo et al. (2010) performed a microarray with neuromasts cells, due to its potential as a model of cell migration and differentiation of sensorial cells from multipotent progenitor cells. They catalogued a variety of biological processes and a wide number of signalling pathways involved in neuromasts and lateral line development. Their work has highlighted genes involved in processes related to cellular migration, the immune system and development in which IL-6 was suggested to be involved.

The data reported so far both in mammals and fish point out the important role that IL-6 appears to have during both development and the immune response. In our work, we have confirmed that zebrafish IL-6 shares structural characteristics with IL-6 from other vertebrates. Its expression appears at an early age in zebrafish larvae, and its pattern of expression following immune stimuli shows similarities with other proinflammatory cytokines. In summary, our results will facilitate the use of this fish species as a model for the study of various pathologies of increasing interest, such as 
cancer and chronic inflammation diseases, in which IL-6 and its receptors have been associated in recent years.

\section{ACKNOWLEDGEMENTS}

We want to thank the funding from the project CSD2007-00002 "Aquagenomics" of the program Consolider-Ingenio 2010 from the Spanish Ministerio de Ciencia e Innovación. M. Varela gratefully acknowledges the JAE Program, co financed by CSIC and European Social Funds, for a predoctoral grant.

\section{REFERENCES}

Akira, S., Hirano, T., Taga, T., Kishimoto, T., 1990. Biology of multifunctional cytokines: IL 6 and related molecules (IL1 and TNF). FASEB J. 4, 2860-2867.

Altschul, S.F., W. Gish, W. Miller, E.W. Myers, and D.J. Lipman. 1990. Basic local alignment search tool. J Mol Biol. 215, 403-410.

Betz, U.A.K., Bloch, W., van den Broek, M., Yoshida, K., Taga, T., Kishimoto, T., Addicks, K., Rajewsky, K., Müller, W. Postnatally Induced Inactivation of gp130 in Mice Results in Neurological, Cardiac, Hematopoietic, Immunological, Hepatic, and Pulmonary Defects. J. Exp. Med. 188, 1955-1965.

Bird, S., Zou, J., Savan, R., Kono, T., Sakai, M., Woo, J., Secombes, C.J., 2005. Characterization and expression analysis of an interleukin 6 homologue in the Japanese pufferfish, Fugu rubripes. Dev. Comp. Immunol. 29, 775-789.

Bryson, K., McGuffin, L.J., Marsden, R.L., Ward, J.J., Sodhi, J.S., Jones, D.T., 2005. Protein structure prediction servers at University College London. Nucleic Acids Res. $33,36-38$.

Castellana, B., Iliev, D.B., Sepulcre, M.P., Mackenzie, S., Goetz, F.W., Mulero, V., Planas, J.V., 2008. Molecular characterization of interleukin-6 in the gilthead seabream (Sparus aurata). Mol. Immunol. 45, 3363-3370. 
Chalaris, A., Garbers, C., Rabe, B., Rose-Jhon, S., Scheller, J., 2011. The soluble interleukin 6 receptor: Generation and role in inflammation and cancer. Eur. J. Cell Biol. 90, 484-494.

Chung, K.W., Ando, M., Adashi, E.Y., 2000. Periovulatory and Interleukin (IL)-1Dependent Regulation of IL-6 in the Immature Rat Ovary: A Specific IL-1 ReceptorMediated Eicosanoid-Dependent Effect. J. Soc. Gynecol. Investig. 7, 301-308.

Gallardo, V.E., Liang, J., Behra, M., Elkahloun, A., Villablanca, E.J., Russo, V., Allende, M.L., Burgess, S.M., 2010. Molecular dissection of the migrating posterior lateral line primordium during early development in zebrafish. BMC Dev. Biol. 10, 120.

Heinrich, P.C., Behrmann, I., Haan, S., Hermanns, H.M., Müller-Newen, G., Schaper, F., 2003. Principles of interleukin (IL)-6-type cytokine signalling and its regulation. Biochem. J. 374, 1-20.

Hibi, M., Murakami, M., Saito, M., Hirano, T., Taga, T., Kishimoto, T., 1990. Molecular cloning and expression of an IL-6 signal transducer, gp130. Cell. 63, 11491157.

Hirano, T., Taga, T., Nakano, N., Yasukawa, K., Kashiwamura, S., Shimizu, K., Nakajima, K., Pyun, K.H., Kishimoto, T., 1985. Purification to homogeneity and characterization of human B-cell differentiation factor (BCDF or BSFp-2). Proc. Natl. Acad. Sci. USA. 82, 5490-5494.

Huising, M.O., Stet, R.J.M., Savelkkoul, H.F.J., Verburg-van Kemenade, B.M., 2004. The molecular evolution of the interleukin-1 family of cytokines; IL-18 in teleost fish. Dev. Comp. Immunol. 28, 395-441.

Iliev, D.B., Castellana, B., MacKenzie, S., Planas, J.V., Goetz, F.W., 2007. Cloning and expression analysis of an IL-6 homolog in rainbow trout (Oncorhynchus mykiss). Mol. Immunol. 44, 1803-1807. 
Ip, N.Y., Nye, S.H., boulton, T.G., Davis, S., Taga, T., Li, Y., Birren, S.J., Yasukawa, K., Kishimoto, T., Anderson, D.J., Stahl, N., Yancopoulos, G.D., 1992. CNTF and LIF act on neuronal cells via shared signaling pathways that involve the IL-6 signal transducing receptor component gp130. Cell. 69, 1121-1132.

Jones, S.A., Horiuchi, S., Topley, N., Yamamoto, N., Fuller, G. M., 2001. The soluble interleukin 6 receptor: mechanisms of production and implications in disease. FASEB J. $15,43-58$.

Liongue, C. and Ward, A.C., 2007. Evolution of Class I cytokine receptors. BMC Evol Biol. 7, 120.

Liu, T.X., Zhou, Y., Kanki, J.P., Deng, M., Rhodes, J., Yang, H.W., Sheng, X.M., Zon, L.I., Look, A.T., 2002. Evolutionary Conservation of Zebrafish Linkage Group 14 with Frequently Deleted Regions of Human Chromosome 5 in Myeloid Malignancies. Proc. Natl. Acad. Sci. USA. 99, 6136-6141.

Mehler, M.F., Kessler, J.A., 1997. Hematolymphopoietic and inflammatory cytokines in neural development. Trends Neurosci. 20, 357-365.

Naka, T., Nishimoto, N., Kishimoto, T., 2002. The paradigm of IL-6: from basic science to medicine. Arthritis Res. 4, S233-S242.

Nam, B.H., Byon, J.Y., Kim, Y.O., Park, E.M., Cho, Y.C., Cheong, J.H., 2007. Molecular cloning and characterization of the flounder (Paralichthys olivaceus) interleukin-6 gene. Fish Shellfish Immunol. 23, 231-236.

Nandurkar, H.H., Hilton, D.J., Nathan, P., Willson, T., Nicola, N., Begley, C.G., 1996. The human IL-11 receptor requires gp130 for signalling: demonstration by molecular cloning of the receptor. Oncogene. 12, 585-93.

Nielsen, H., Engelbrecht, J., Brunak, S., von Heijne, G., 1997. Identification of prokaryotic and eukaryotic signal peptides and prediction of their cleavage sites. Protein Eng. 10, 1-6. 
Nüsslein-Volhard, C. and Dahm, R., 2002. Zebrafish: a practical approach. New York: Oxford University Press.

Pearson, W.R., Lipman, D.J., 1988. Improved tools for biological sequence comparison. Proc Natl Acad Sci USA. 85, 2444-2448.

Pfaffl, M.W., 2001. A new mathematical model for relative quantification in real-time RT-PCR. Nucleic Acids Res. 29, e45.

Pieper, U., Webb, B.M., Barkan, D.T., Schneidman-Duhovny, D., Schlessinger, A., Braberg, H., Yang, Z., Meng, E.C., Pettersen, E.F., Huang, C.C., Datta, R.S., Sampathkumar, P., Madhusudhan, M.S., Sjölander, K., Ferrin, T.E., Burley, S.K., Sali, A., 2011. ModBase, a database of annotated comparative protein structure models, and associated resources. Nucleic Acids. Res. 39, D465-D474.

Postlethwait, J.H., Woods, I.G., Ngo-Hazelett, P., Yan, Y.-L., Kelly, P.D., Chu, F., Huang, H., Hill-Force, A., and Talbot, W.S., 2000. Zebrafish comparative genomics and the origins of vertebrate chromosomes. Genome Res. 10, 1890-1902.

Rose-John, S., Scheller, J., Elson, G., Jones, S.A., 2006. Interleukin-6 biology is coordinated by membrane-bound and soluble receptors: role in inflammation and cancer. J. Leuk. Biol. 80, 227-236.

Rost, B., Yachdav, G., Liu, J., 2004. The PredictProtein Server. Nucleic Acids Res. 32, 321-326.

Roy, A., Kucukural, A., Zhang, Y., 2010. I-TASSER: a unified platform for automated protein structure and function prediction. Nat. Protoc. 5, 725-738.

Rozen, S., Skaletsky, H., 2000. Primer3 on the WWW for general users and for biologist programmers. Methods Mol. Biol. 132, 365-386. 
Saitou, N., Nei, M., 1987. The neighbor-joining method: a new method for reconstructing phylogenetic trees. Mol Biol Evol. 4, 406-425.

Santos, M.D., Yasuike, M., Kondo, H., Hirono, I., Aoki, T., 2007. A novel type-1 cytokine receptor from fish involved in the Janus kinase/Signal transducers and activators of transcription (Jak/STAT) signal pathway. Mol. Immunol. 44, 3355-63.

Scheller, J., Chalaris, A., Schmidt-Arras, D., Rose-John, S., 2011. The pro- and antiinflammatory properties of the cytokine interleukin-6. Biochim. Biophys. Acta. 1813, 878-888.

Schirmacher, P., Peters, M., Ciliberto, G., Blessing, M., Lotz, J., zum Büschenfelde, K. M., Rose-John, S., 1998. Hepatocellular hyperplasia, plasmacytoma formation, and extramedullary hematopoiesis in interleukin (IL)-6/soluble IL-6 receptor doubletransgenic mice. Am. J. Pathol. 153, 639-648.

Schooltinck, H., Schmitz-Van de Leur, H., Heinrich, P.C., Rose-John, S., 1992. Upregulation of the interleukin-6-signal transducing protein (gp130) by interleukin-6 and dexamethasone in HepG2 cells. FEBS Lett. 297, 263-265.

Snyers, L., Content, J., 1992. Enhancement of IL-6 receptor $\beta$ chain (gp130) expression by IL-6, IL-1 and TNF in human epithelial cells. Biochem. Biophys. Res. Commun. 185(3), 902-908.

Spooren, A., Kolmus, K., Laureys, G., Clinckers, R., De Keyser, J., Haegeman, G., Gerlo, S., 2011. Interleukin-6, a mental cytokine. Branin Res. Rev. 67, 157-183.

Strauss, W. M., 2001. Preparation of genomic DNA from mammalian tissue. In: J.E. Coligan, B. Bieres, D. H. Margulies, E. M. Shevach, W. Strober and R. Coico, Editors, Protoc Immunol

Szelényi, J., 2001. Cytokines and the central nervous system. Brain Res. Bull. 54, 329338. 
Taga, T., Fukuda, S., 2005. Role of IL-6 in the neural stem cell differentiation. Clin. Rev. Allergy Immunol. 28, 249-256.

Tamura, K., Peterson, D., Peterson, N., Stecher, G., Nei, M., Kumar, S., 2011. MEGA5: Molecular Evolutionary Genetics Analysis using Maximum Likelihood, Evolutionary Distance, and Maximum Parsimony Methods. Mol. Biol. Evol. doi: 10.1093/molbev/msr121.

Thisse, C., Thisse, B., 2008. High-resolution in situ hybridization to whole-mount zebrafish embryos. Nat. Protoc. 3, 59-69.

Vallières, L., Rivest, S., 1997. Regulation of the Genes Encoding Interleukin-6, Its Receptor, and gpl3O in the Rat Brain in Response to the Immune Activator Lipopolysaccharide and the Proinflammatory Cytokine Interleukin- 1 B. J. Neurochem. $69,1668-1683$.

Wallenius, V., Wallenius, K., Ahrén, B., Rudling, M., Carlsten, H., Dickson, S.L., Ohlsson, C., Jansson, J., 2002. Interleukin-6-deficient mice develop mature-onset obesity. Nat. Med. 8, 75-79.

Westerfield, M., 2000. The Zebrafish Book; A Guide for the Laboratory Use of Zebrafish (Danio rerio). Eugene, OR: University of Oregon Press.

Yoshida, K., Taga, T., Saito, M., Suematsu, S., Kumanogoh, A., Tanaka, T., Fujiwara, H., Hirata, M., Yamagami, T., Nakahata, T., Hirabayashi, T., Yoneda, Y, Tanaka, K, Wang, W.Z., Mori, C., Shiota, K., Yoshida, N., Kishimoto, T., 1996. Targeted disruption of gp130, a common signal transducer for the interleukin 6 family of cytokines, leads to myocardial and hematological disorders. Proc. Natl. Acad. Sci. USA. 93, 407-411.

Zhang, Y., 2007. Template-based modeling and free modeling by I-TASSER in CASP7. Proteins. 69, 108-117. 


\section{FIGURE LEGENDS}

Figure 1: Zebrafish IL-6 gene organization. (a) Comparative gene location diagram among Takifugu rubripes (scaffold 449), Homo sapiens (chromosome 7) and Danio rerio (chromosome 19). Arrows above genes indicate the gene orientation. (b) Comparison of the gene organization and exon sizes (bp) among fish IL-6 sequences and some higher vertebrates IL-6. Sequences accession numbers are indicated in Material and methods.

Figure 2: ORF and predicted amino acid sequence of zebrafish IL-6. The start and stop codons are boxed and the predicted signal peptide is underlined. The IL-6 domain is in bold. The IL-6 family signature (C-X(9)-C-X(6)-GL-X(2)-Y-X(3)-L) is shaded. Predicted N-glycosylation sites appear underlined with a dashed line.

Figure 3: Amino acid alignment and phylogenetic relationship. (a) Multiple alignment of zebrafish IL- 6 with other vertebrate IL- 6 proteins. The location of the four alpha-helices (A-D) is indicated above the sequence for human IL-6 and under the sequence for predicted zebrafish IL-6 with a dotted line. IL-6 family signature is shaded and arrows indicate the cysteine residues involved in disulfide bond formation. (b) Phylogenetic tree based on deduced amino acid sequences of different vertebrate IL-6 family molecules. This unrooted tree was constructed using the Neighbour-Joining algorithm, bootstrapped 10,000 times. Sequences accession numbers are indicated in Material and methods.

Figure 4: Predicted tertiary structure of zebrafish IL-6 compared with human IL6. (a) Danio rerio IL-6 predicted tertiary structure. (b) Homo sapiens IL-6 tertiary structure. (c) Comparison of the zebrafish and human IL-6 tridimensional structures. The alignments were conducted using Modweb, ModBase and Pymol. The protein structure modelling was conducted using 3D-JIGSAW and I-TASSER selecting the model with the best $\mathrm{C}$-score.

Figure 5: Zebrafish IL-6, IL-6R and gp130 tissue-related expression. Expression levels of IL-6, IL-6R and gp130 genes in organs of non-stimulated adult zebrafish. All qPCR reactions were carried out as technical triplicates and the expression level of analysed genes was normalized using the $18 \mathrm{~S}$ rRNA. The expression levels were calculated by dividing the normalized expression values of each organ by the normalized expression values of liver. Each bar represents the mean and standard error of three biological replicates. $* 0.01<\mathrm{p}<0.05$

Figure 6: Time course of IL-6, TNF- $\alpha$, IL-1 $\beta$, IL-6R and gp130 expression after stimulation with PAMPs. Expression of IL-6, TNF- $\alpha$, IL-1 $\beta$, IL-6R and gp130 genes in zebrafish kidney after $1 \mathrm{mg} / \mathrm{ml}$ LPS (above) or $1 \mathrm{mg} / \mathrm{ml}$ poly I:C (below) intraperitoneal injection at 3,6 and 24 hours post-stimulation. All qPCR reactions were carried out as technical triplicates and the expression level of analysed genes was normalized using the $18 \mathrm{~S}$ rRNA. Fold change units were calculated by dividing the normalized expression values of stimulated zebrafish kidneys by the normalized expression values of the controls for each of the time points. Each bar represents the 
mean and standard error of three biological replicates. $* 0.01<\mathrm{p}<0.05, * * 0.001<\mathrm{p}<0.01$ and $* * * 0.0001<\mathrm{p}<0.001$

Figure 7: Ontogeny of IL-6, IL-6R and gp130 genes. Expression levels of IL-6, IL$6 \mathrm{R}$ and gp130 genes during the zebrafish larvae development. All qPCR reactions were carried out as technical triplicates and the expression level of analysed genes was normalized using the 18S rRNA. Expression levels were calculated by dividing the normalized expression values of each sample point by the normalized expression values at $2 \mathrm{dpf}$ larvae. Each bar represents the mean and standard error of two biological replicates. $* 0.01<\mathrm{p}<0.05$ and $* * 0.001<\mathrm{p}<0.01$

Figure 8: In situ hybridisation on 3 dpf zebrafish embryos. (a-c) Expression pattern of IL-6, IL-6R and gp130 genes in embryos hybridized with the antisense probe. (d) Control embryos hybridized with the sense probe. (e) Dorsal larvae view. (f) Infraorbital zone detail. (g) Lateral view of a larvae head. (h) Detail of neuromasts of the posterior lateral line system. Images from $8 \mathrm{e}$ to $8 \mathrm{~h}$ are representative of the three studied genes. D1-2, dorsal lateral line neuromast; IO1-4, infraorbital lateral line neuromast; lf, lateral fin; M2, mandibular lateral line neuromast; m, mouth opening; MI1-2, middle lateral line neuromast; O1-2, otic lateral line neuromast; OC1, occipital lateral line neuromast; op, olfactory placode; P1-7, posterior lateral line neuromast; SO1-3, supraorbital lateral line neuromast. 
Table 1.

Oligonucleotides sequences.

\begin{tabular}{|c|c|c|}
\hline \multicolumn{3}{|c|}{ IL-6 characterisation } \\
\hline Name of primer & Primer sequence $\left(5^{\prime} \rightarrow 3^{\prime}\right)$ & Amplicon size (bp) \\
\hline IL-6 ORFF & ATGCCATCCGCTCAGAGT & 696 \\
\hline IL-6 ORFR & TTAGTTCTTGTCAGCGCTGC & \\
\hline IL-6 gen $1 F$ & ATGCCATCCGCTCAGAGT & 713 \\
\hline IL-6 gen1R & GCGTCAGGTTTACTCACTT & \\
\hline IL-6 gen2F & TTTGCTTACAGAAGATTCAAG & 1104 \\
\hline IL-6 gen $2 \mathrm{R}$ & ATATGGACAAACACAAACTGT & \\
\hline IL-6 gen $3 \mathrm{~F}$ & TCTTTATCAAATACGCAACAG & 968 \\
\hline IL-6 gen3R & СТTCССТTTTTCCAGCATTT & \\
\hline IL-6 gen4F & GCTGAATCAACGCAATTCTT & 379 \\
\hline IL-6 gen4R & CTGTTAGTTCTTGTCAGCG & \\
\hline \multicolumn{3}{|c|}{ 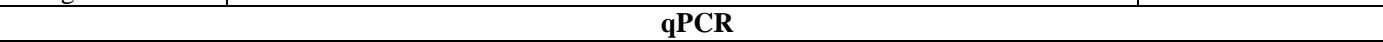 } \\
\hline Name of primer & Primer sequence $\left(5^{\prime} \rightarrow 3^{\prime}\right)$ & Amplicon size (bp) \\
\hline IL-6 F & TCAACTTCTCCAGCGTGATG & 73 \\
\hline IL-6 R & TCTTTCССТCTTTTCСТCCTG & \\
\hline IL-6R F & GCCAACTGCAACATACCAAA & 136 \\
\hline IL-6R R & ACTGACAGCACGCAAAACTC & \\
\hline gp130 F & TTCCTGTTCCTGAGCGTCTT & 120 \\
\hline gp130 R & AGGTGACCAGTGGGCAATAG & \\
\hline $\mathrm{TNF} \alpha \mathrm{F}$ & ACCAGGCCTTTTCTTCAGGT & 148 \\
\hline $\mathrm{TNF} \alpha \mathrm{R}$ & GCATGGCTCATAAGCACTTGTT & \\
\hline $\mathrm{IL}-1 \beta \mathrm{F}$ & TTCCCCAAGTGCTGCTTATT & 149 \\
\hline $\mathrm{IL}-1 \beta \mathrm{R}$ & AAGTTAAAACCGCTGTGGTCA & \\
\hline $18 \mathrm{~S} \mathrm{~F}$ & ACCACCCACAGAATCGAGAAA & 97 \\
\hline $18 \mathrm{~S} \mathrm{R}$ & GCCTGCGGCTTAATTTGACT & \\
\hline \multicolumn{3}{|c|}{ in situ hybridisation } \\
\hline Name of primer & Primer sequence $\left(5^{\prime} \rightarrow 3^{\prime}\right)$ & Amplicon size (bp) \\
\hline $\begin{array}{l}\text { IL-6 senseF } \\
\text { IL-6 senseR }\end{array}$ & $\begin{array}{l}\text { ACGATTAGGTGACACTATAGAAATGCCATCCGCTCAAGAAAAC } \\
\text { TTAGTTCTTGTCAGCGCTGC }\end{array}$ & 718 \\
\hline IL-6 antisenseF & ATGCCATCCGCTCAGAAAAC & 720 \\
\hline IL-6 antisenseR & AGTTAATACGACTCACTATAGGGATTAGTTCTTGTCAGCGCTGC & \\
\hline IL-6R senseF & ACGATTTAGGTGACACTATAGAATGTGCCAACTGCAACATACC & 717 \\
\hline IL-6R senseR & AGTTGAGTACAGGGCTCATC & \\
\hline IL-6R antisenseF & TGTGCCAACTGCAACATACC & 719 \\
\hline IL-6R antisenseR & AGTTAATACGACTCACTATAGGGAAGTTGAGTACAGGGCTCATC & \\
\hline $\begin{array}{l}\text { gp130 senseF } \\
\text { gp130 senseR }\end{array}$ & $\begin{array}{l}\text { ACGATTTAGGTGACACTATAGAACAGCACCTGTAAACAGAGTC } \\
\text { TTCTTCTGGTGGCACTTCCA }\end{array}$ & 713 \\
\hline gp130 antisenseF & CAGCACCTGTAAACAGAGTC & 715 \\
\hline gp130 antisenseR & AGTTAATACGACTCACTATAGGGATTCTTCTGGTGGCACTTCCA & \\
\hline
\end{tabular}


Table 2.

Protein sequences comparison among IL-6 molecules.

\begin{tabular}{|c|c|c|c|c|c|c|c|c|}
\hline \multicolumn{9}{|c|}{ Identities (\%) } \\
\hline & H. sapiens & M. musculus & G. gallus & T. rubripes & P. olivaceus & S. aurata & O. mykiss & D. rerio \\
\hline H. sapiens & 100 & 40.8 & 29 & 16.9 & 17.4 & 14.1 & 16.8 & 15.1 \\
\hline M. musculus & & 100 & 21.9 & 12.6 & 11.8 & 15.8 & 14.4 & 12.5 \\
\hline G. gallus & & & 100 & 16.9 & 15.9 & 14.8 & 14.5 & 17.7 \\
\hline T. rubripes & & & & 100 & 45.2 & 49.6 & 23.6 & 16.5 \\
\hline P. olivaceus & & & & & 100 & 47 & 23.4 & $\mathbf{1 7 . 5}$ \\
\hline S. aurata & & & & & & 100 & 21.4 & 17.1 \\
\hline O. mykiss & & & & & & & 100 & 21.5 \\
\hline \multicolumn{9}{|c|}{ Similarities (\%) } \\
\hline & H. sapiens & M. musculus & G. gallus & T. rubripes & P. olivaceus & S. aurata & O. mykiss & D. rerio \\
\hline H. sapiens & 100 & 71.4 & 51 & 38.1 & 40.2 & 36 & 41.8 & 33.6 \\
\hline M. musculus & & 100 & 47.5 & 34.6 & 36.3 & 37.2 & 40.3 & 31.4 \\
\hline G. gallus & & & 100 & 33.9 & 33.8 & 31.6 & 35.3 & 34.6 \\
\hline T. rubripes & & & & 100 & 64.2 & 66 & 46 & 40 \\
\hline P. olivaceus & & & & & 100 & 62.6 & 47.2 & 37.9 \\
\hline S. aurata & & & & & & 100 & 42.3 & 34.7 \\
\hline O. mykiss & & & & & & & 100 & 43 \\
\hline
\end{tabular}


Click here to download high resolution image

a
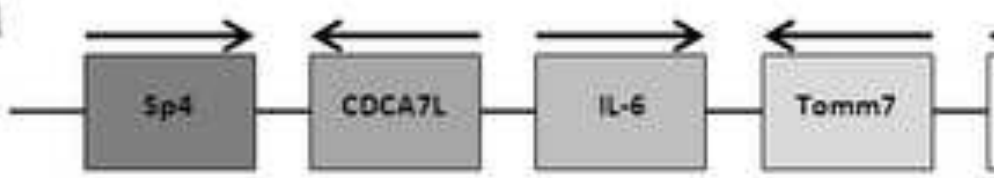

Hyecin

Takifugu rubripes Scaffold 449
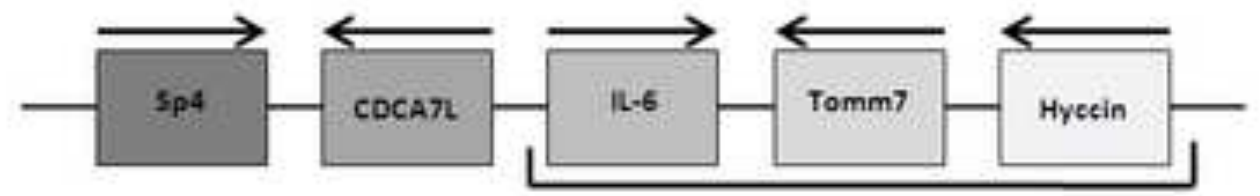

Homo sapiens Chr 7
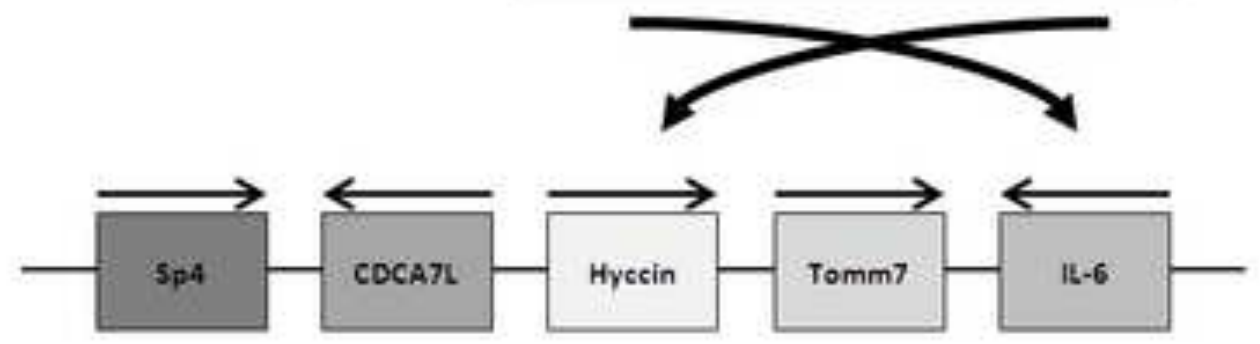

Danio rerio Chr 19

b
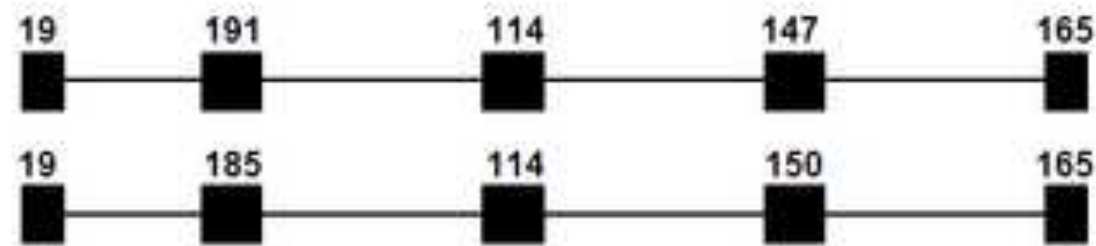

Homo saplens

Mus musculus

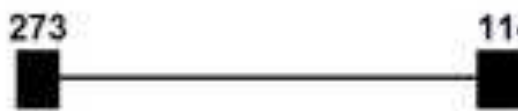

147

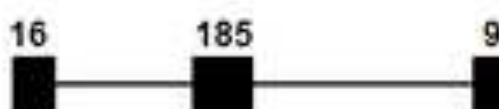

99

144

240
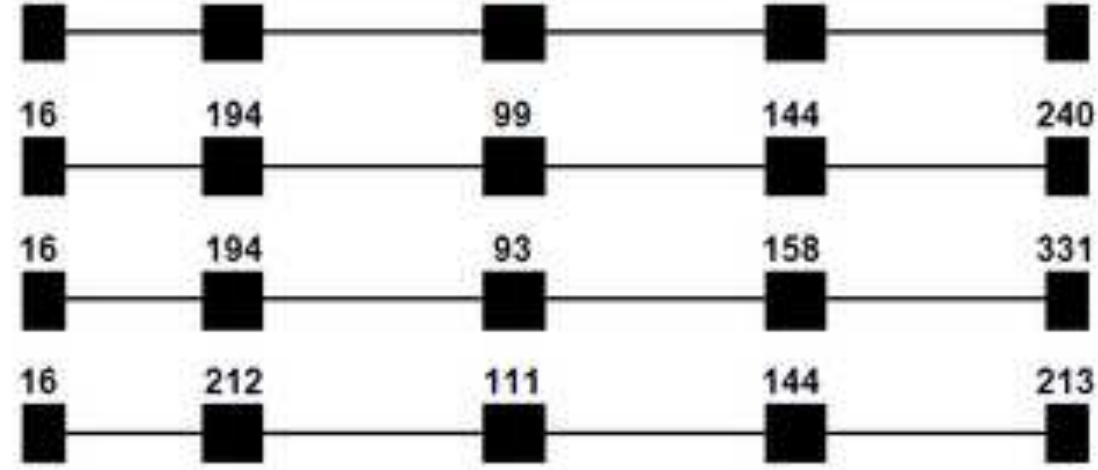

Sparus aurata

Danio rerio

Figure 1 
+1 iägöcatccgctcagaaacagtgctattcctgtctgctacactggctacactcttcatg

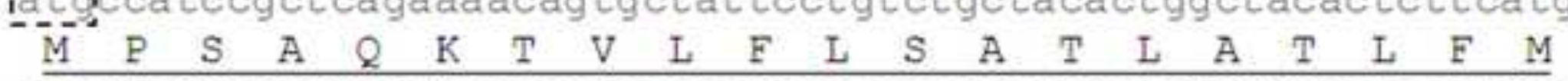

+61 agtctcgctgacccggtccccgtgttcagcagtatgggggaactatccgaaatatctgga

+121 gacgaagttcaggatgtggacgtaaagagtctccttggcgaccggcagaagtggcatctg

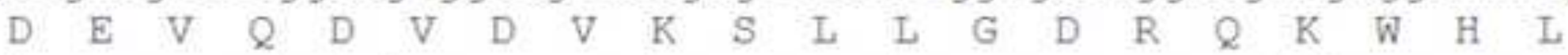

+181 atggccagagatctgtacaaggacgtgaagacactcagagacgagcagtttgagagagat $\begin{array}{llllllllllllllllllll}M & A & R & D & L & Y & K & D & V & K & T & L & R & D & E & Q & F & E & R & D\end{array}$

+241 ttcagagagatggtgaacatgacggcatttgaaggggtcaggatcagcactcctctcctc $\begin{array}{llllllllllllllllllll} & R & E & M & V & N & M & T & A & F & E & G & V & R & I & S & T & P & L & L\end{array}$

+301 aaaccttcagaccgetgcctgtctaaaacttcagcacggaaagatgtctaacgcgaatc $\begin{array}{llllllllllllllllllll}K & P & S & D & R & C & L & S & K & N & F & S & T & E & R & C & L & T & R & I\end{array}$

+361 tacagcgtcctgacgtggtataaagacaactggaactacattgagaaggaaatctgacc

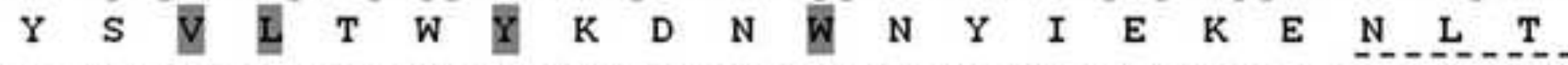
+421 tcagtcctggtgaacgacatcaaacacagcaccaaacgactgctggaggccataaacagc $\begin{array}{llllllllllllllllllll}\mathbf{S} & \text { V } & \text { L } & \text { V } & \text { N } & \text { D } & \text { I } & \text { K } & \text { H } & \text { S } & \text { T } & \text { K } & \text { R } & \text { L } & \text { L } & \text { E } & \text { A } & \text { I } & \text { N } & S\end{array}$

+481 cagctgcaggtgagagacggagagatggatcagacatccagcacttccctatcctttaaa $\begin{array}{llllllllllllllllllll}Q & L & Q & V & R & D & G & E & M & D & Q & T & S & S & T & S & L & S & F & K\end{array}$

+541 tccgcatggactcgcaagacgacggtccactcgatcctgttcaacttctccagcgtgatg $\begin{array}{lllllllllllllllllllll}S & A & W & T & R & K & T & T & V & H & S & I & L & F & & N & F & S & S & V & M\end{array}$

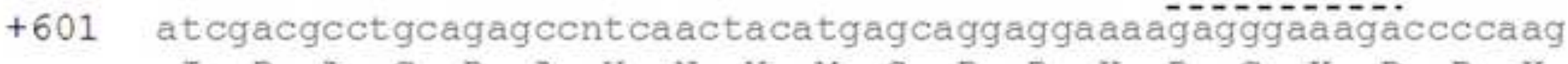
$\begin{array}{lllllllllllllllllllll}I & D & A & C & R & A & X & N & Y & M & S & R & R & K & R & G & K & D & P & K\end{array}$

+661 aggaccggagactggggcagcgctgacaagaadtaa

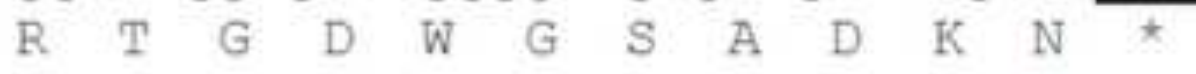

Figure 2 
Figure 3

Click here to download high resolution image

a

$x \geq-1 \leq 6$

Na-1L6

og-IL6

$7 x-1: 6$

fo-z: 6

Sa-1L6

ce-126

DE-126

Ha-12.

m-1L6

G9-1:6

Tr-tte

Do-1L6

sa- 526

cm-1:6

De-1L6

H $x$-IL6

Nen-12E

Gg-1t.

I $=7: 6$

Fo-1t6

$5:-126$

Cक-1:6

Dr-1te

Hz- $\mathrm{x} \pm \mathrm{e}$

pan-7L6

Gg-1Le

Tr-1L6

Do-1Le

5a-1te

ca-ILE

Dr-126

Ha-1Le

서-IL6

Go-126

Tr-ILE

คo-ILE

sa-1:6

Con-126

Dr-1te

b

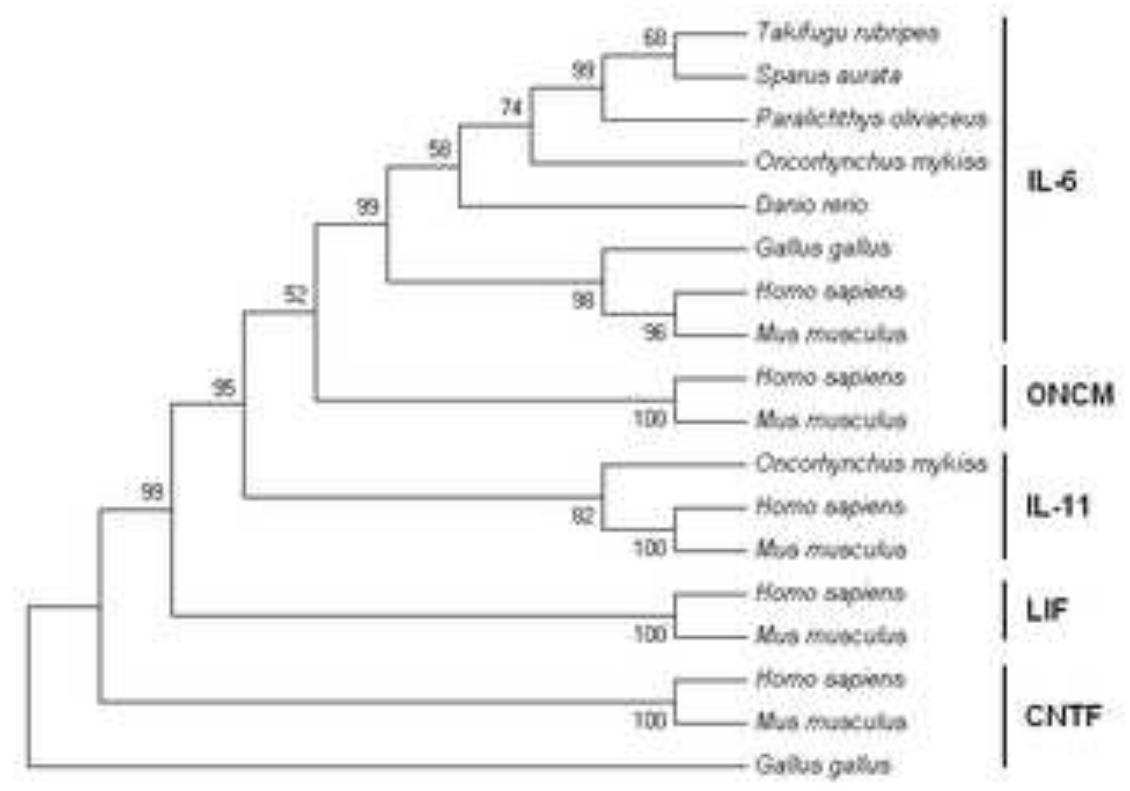

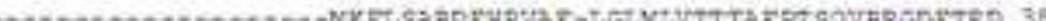

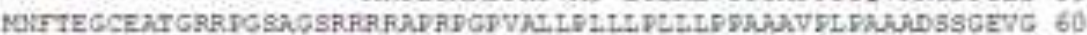

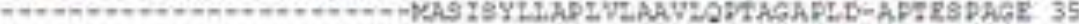

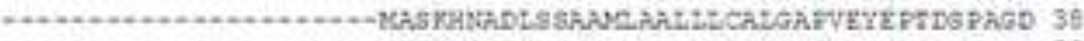

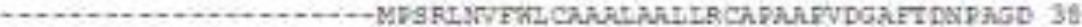

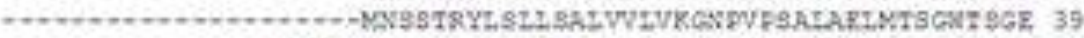

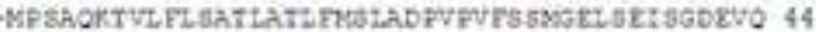

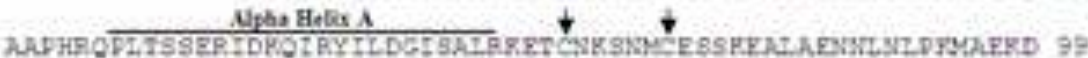

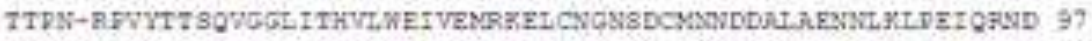

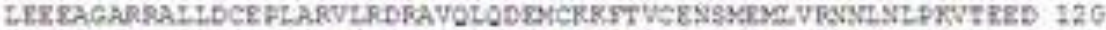

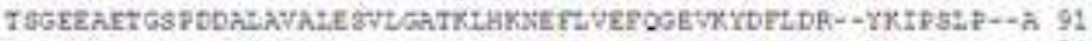

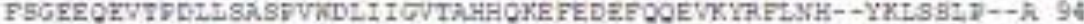

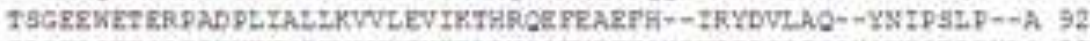

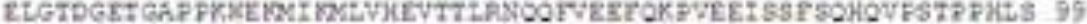

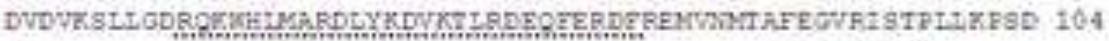

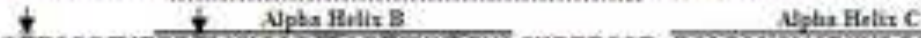

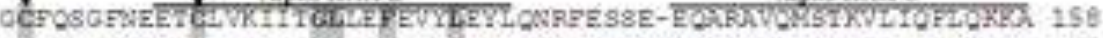

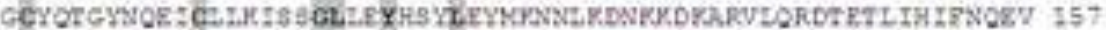

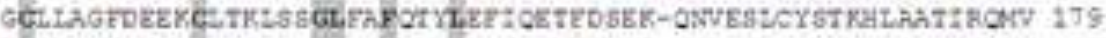

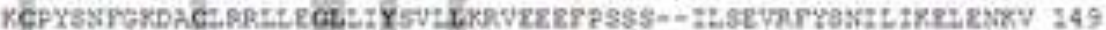

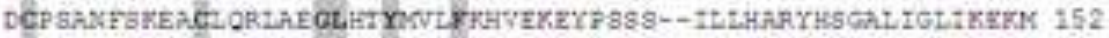

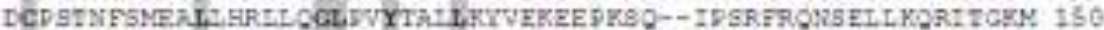

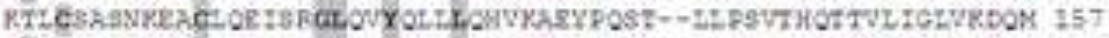

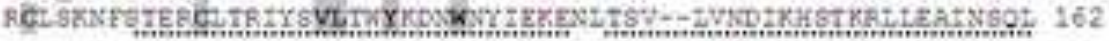
Shen Helix D

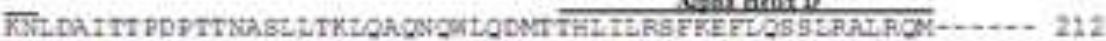

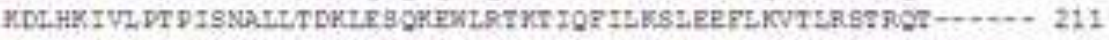

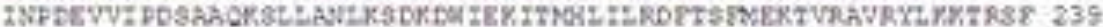

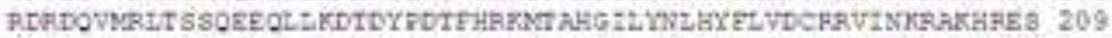

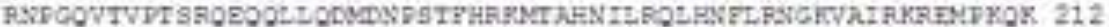

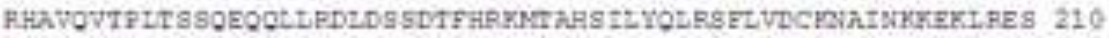

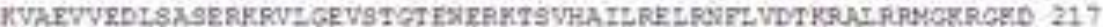

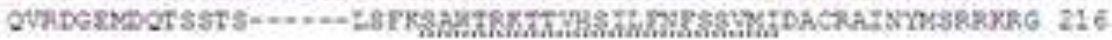

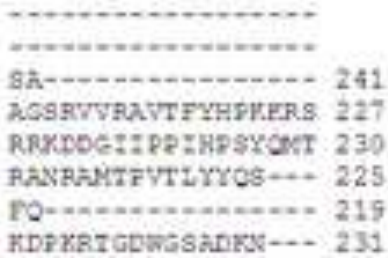




\section{Figure 4 \\ Click here to download high resolution image}

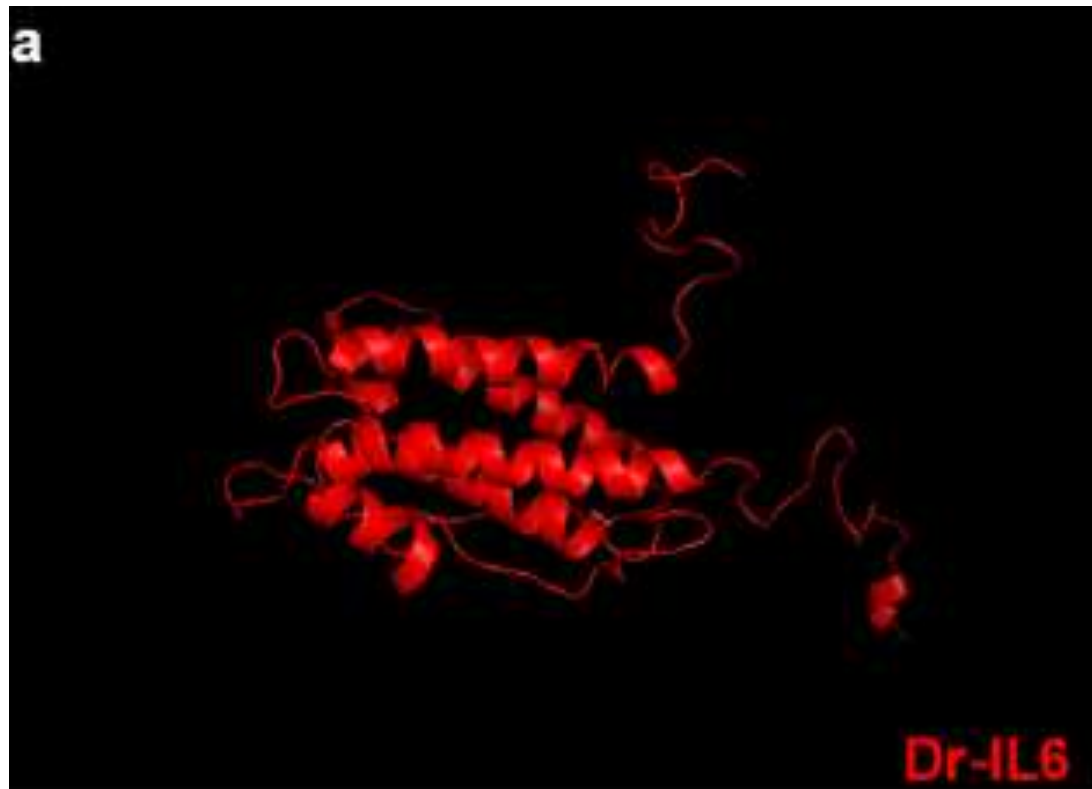

b

Hs-IL6

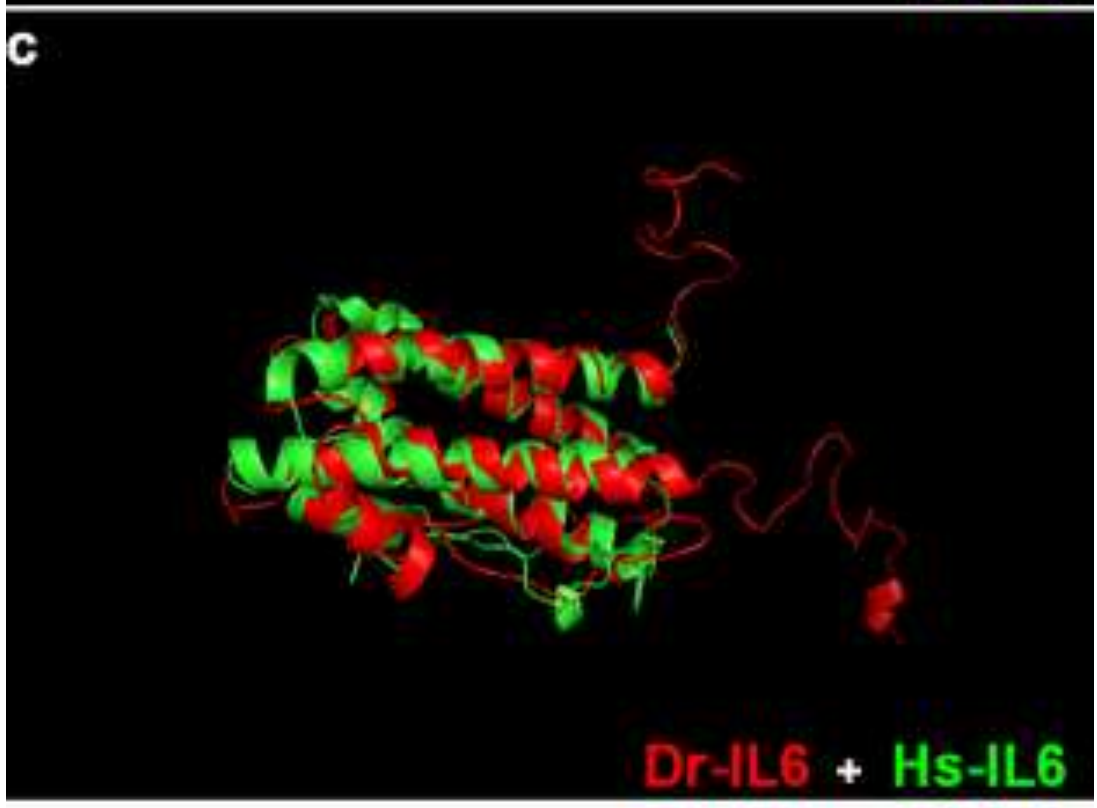

Figure 4 

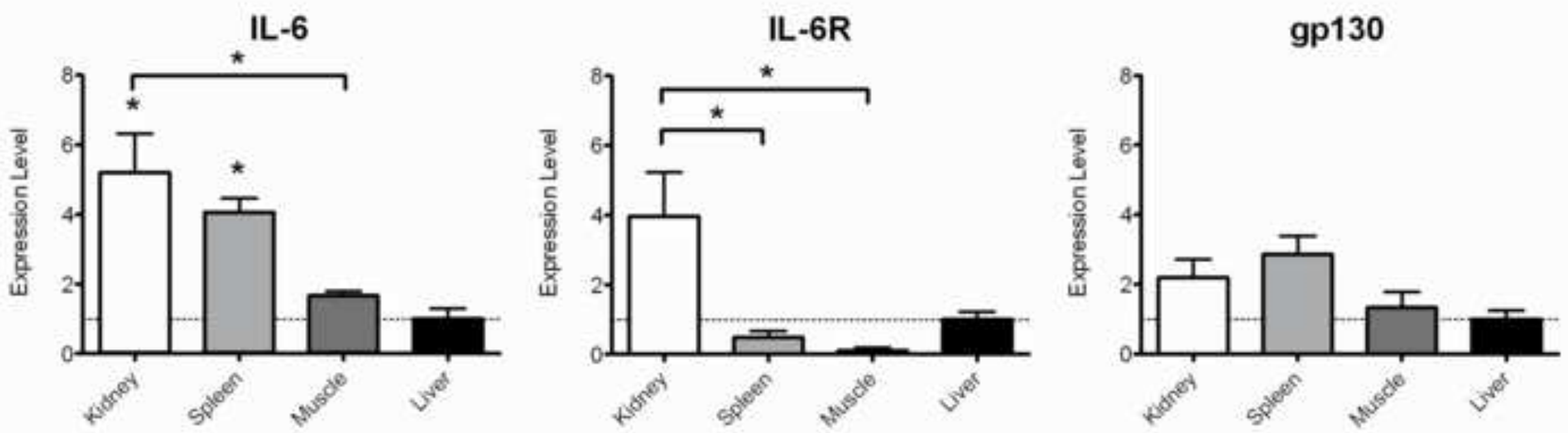

Figure 5 

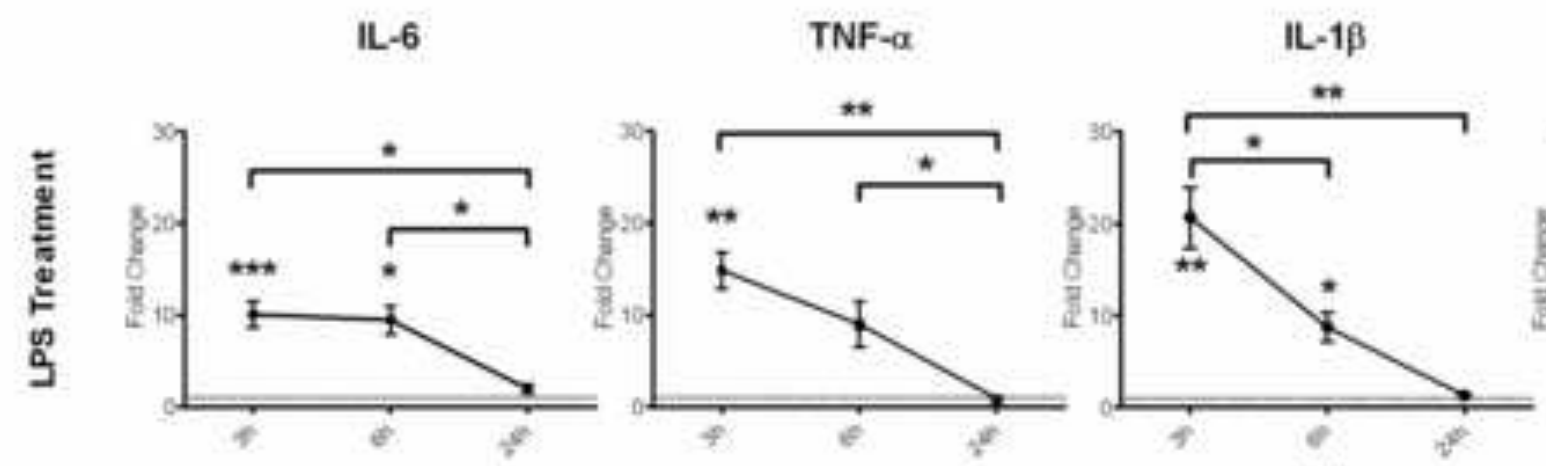

IL-6R

gp130
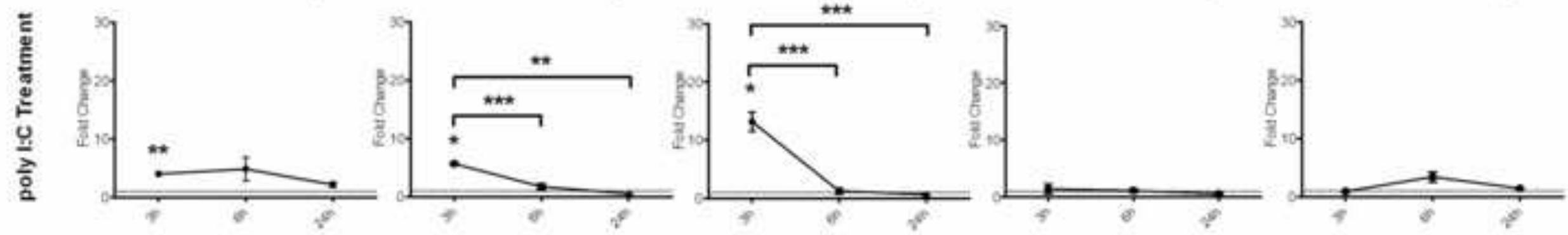

Figure 


\section{IL-6}

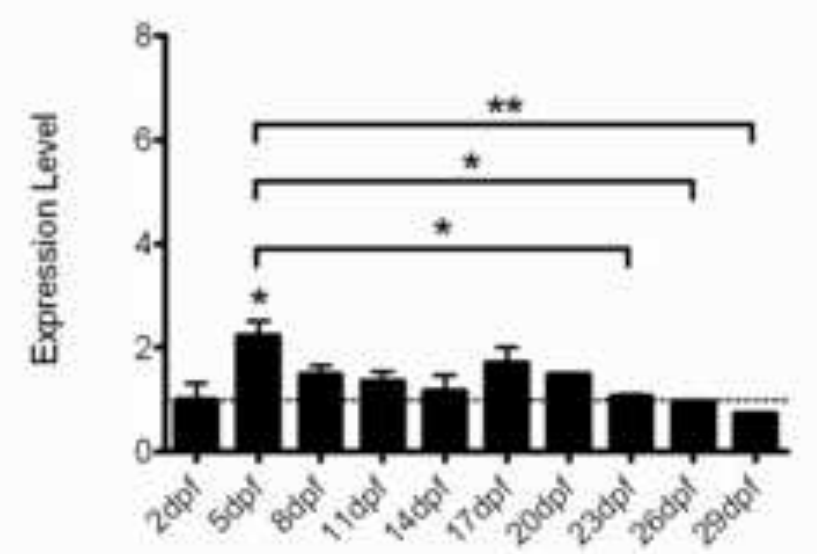

IL-6R

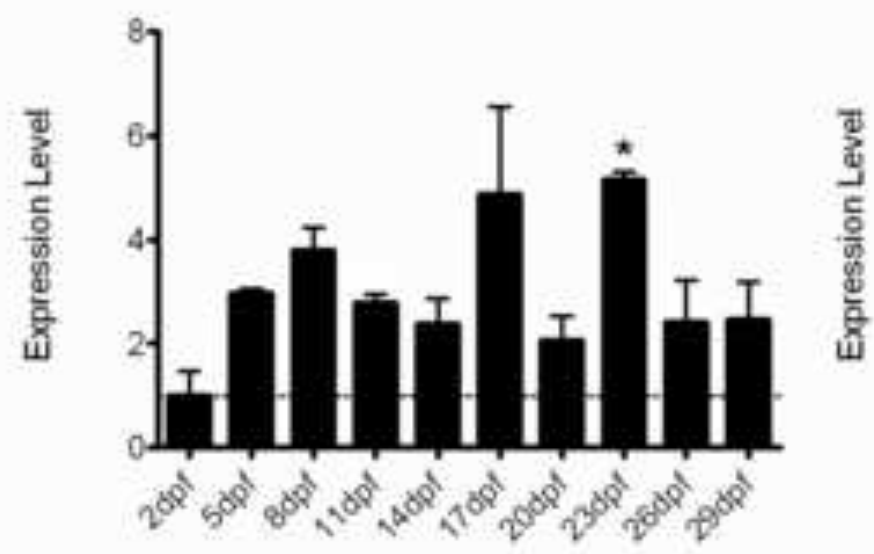

gp130

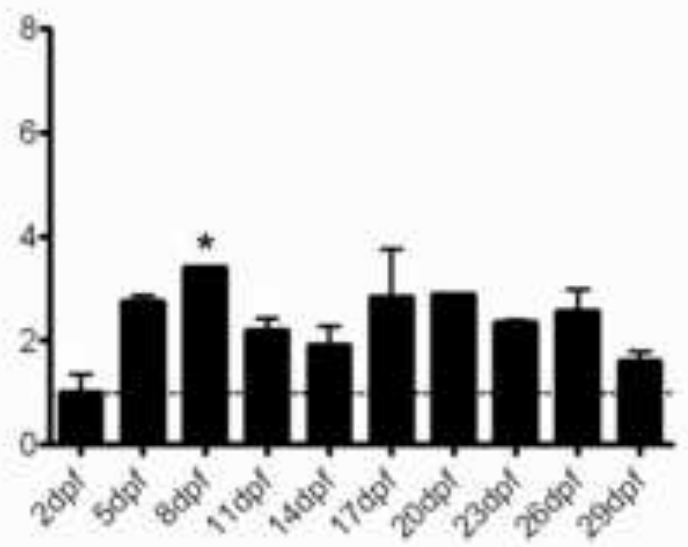

Figure 7 
Figure 8
Click here to download high resolution image

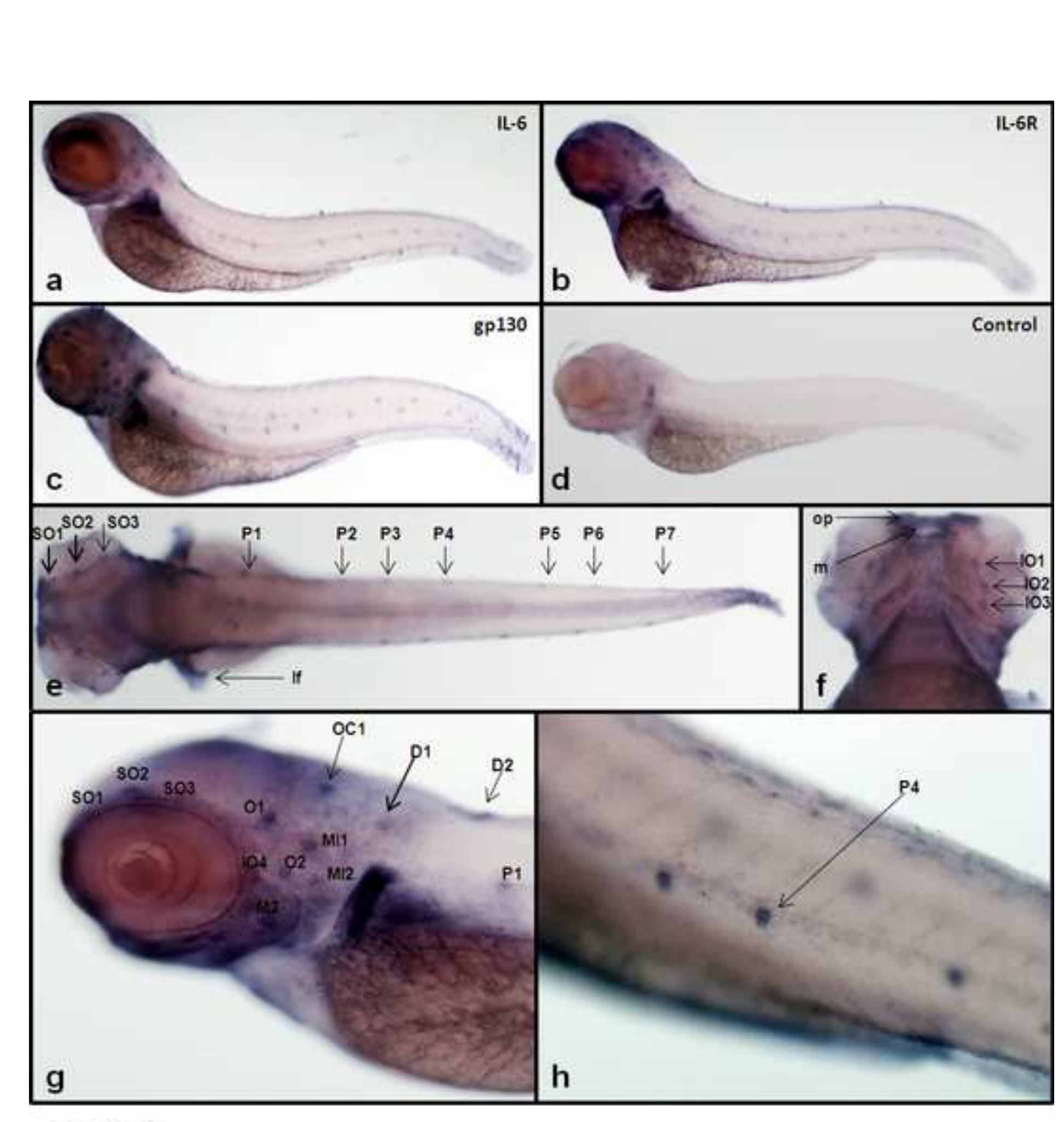

Figure 8

8

Click here to download high resolution image

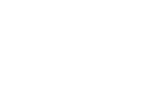

(1)

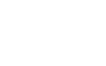

(n)
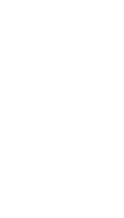

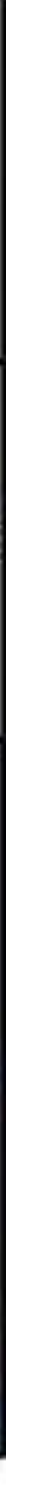

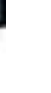

